\title{
Por que é tão difícil democratizar a gestão da escola pública? ${ }^{1}$
}

\section{Why is it so difficult to democratize public school management?}

\author{
Licínio C. Lima*
}

\begin{abstract}
RESUMO
Apesar da consagração legal no plano das orientações para a ação - desde os textos constitucionais, passando pelas leis de bases da educação, até à legislação ordinária e aos discursos políticos -, a gestão democrática da escola pública permanece como uma realização difícil de alcançar no plano da ação organizacional efetiva, em cada escola concreta. Sendo muito relevantes, até como resultado da democratização política que afastou regimes autoritários, os referenciais jurídicos democráticos são, porém, insuficientes para garantir a democratização da gestão escolar. Neste texto são apresentados alguns dos obstáculos políticos e organizacionais, também históricos e culturais, que têm dificultado a concretização de uma gestão democrática das escolas, incluindo uma análise crítica sobre o próprio conceito e sobre as suas exigências mais substantivas.
\end{abstract}

Palavras-chave: Gestão democrática. Gestão escolar. Democracia.

\begin{abstract}
Despite its legal consecration in terms of the guidelines for action - from the constitutional texts and the basic education laws to the ordinary legislation and political discourses -, democratic management of the public school remains difficult to achieve at the level of effective organizational action in each concrete school. Although highly relevant, as a result of political democratization that has driven authoritarian regimes away, democratic legal referentials are still insufficient to guarantee the democratization of school
\end{abstract}

1 Este trabalho contou com o apoio de Fundos Nacionais através da Fundação para a Ciência e a Tecnologia (FCT) no âmbito do projeto PEst-OE/CED/UI1661/2014 do CIEd-UM.

* Instituto de Educação da Universidade do Minho. Centro de Investigação em Educação. Braga, Portugal. E-mail: 1lima@ie.uminho.pt. https://orcid.org/0000-0003-0899-7987 
management. This paper presents some of the political and organizational obstacles, as well as historical and cultural, that have hampered the democratic management of schools, including a critical analysis of the concept itself and its most substantive demands.

Keywords: Democratic management. School management. Democracy.

\section{Introdução: democratização política e democratização da gestão escolar}

A pergunta formulada no título deste texto encerra pressupostos que exigem clarificação, tanto mais quanto se reconhece que tais pressupostos estão longe de ser consensuais. Bastará pensar, entre outras posições possíveis, em duas perspectivas tipicamente antagónicas sobre a matéria. A primeira, por exemplo, partindo da tese de que a gestão democrática das escolas, por se encontrar legalmente assegurada, encontra-se também empiricamente concretizada, com maiores ou menores graus de realização em cada contexto escolar concreto. Em qualquer caso, remete para uma aquisição democrática que não deve ser questionada de forma hiperbólica: a gestão democrática das escolas representaria uma conquista democrática efetiva e não tão problemática a ponto de ser razoável admitir tantas dificuldades na sua consecução. A segunda, assumindo que a interrogação inicial não faz qualquer sentido, dado que, mais do que de um problema de dificuldade de democratização, se deveria partir da tese da impossibilidade, uma vez que a gestão democrática estaria associada a um ideal normativo impraticável e inapropriado em termos de eficiência e de eficácia, de competitividade e de qualidade. Nesse caso, a gestão democrática das escolas seria considerada uma irracionalidade em termos de uma gestão moderna, profissional e altamente exigente, incompatível com a falta de competência técnica da liderança e com formas de participação dos não especialistas em gestão. Ao invés, o direito de gerir por parte de gestores profissionais seria crucial, sendo depois avaliado em função do programa político estabelecido e dos resultados obtidos, comparados com os objetivos e os resultados contratualizados junto das autoridades políticas e de outros interessados ("stakeholders"), aí se incluindo, por exemplo, as famílias dos alunos.

Embora apenas esquematicamente apresentadas, cada perspectiva é passível de múltiplas graduações em termos de política educacional, de teorias de gestão, de ideários educativos, de práticas em contexto escolar, ambas sendo mais frequentes do que geralmente se supõe. 
A primeira, de feição formalista, tende a operar uma correspondência perfeita entre o plano das orientações para a ação e o plano da ação organizacional, pressupondo que as regras formais legais são necessariamente transformadas em regras efetivamente atualizadas (LIMA, 2011, p. 54-75). Trata-se de uma abordagem tradicional, de cariz positivista, subordinando a ação organizacional escolar à mera reprodução de regras legais e outras de tipo prescritivo, frequente em estudos de teor legalista e normativista que, no Brasil e em Portugal, foram realizados sobretudo durante os regimes políticos autoritários (ver, entre outros, os estudos de LIMA, 1991, 1997; SANDER, 1995; BARROSO, 1997; SILVA, 2006; SOUZA, 2008; TORRES; LIMA, 2017). Por um lado, isso resultou da falta de elaboração teórica e da ausência de pesquisas empíricas sobre gestão escolar; por outro lado, visou objetivos de reprodução política e de socialização dos atores escolares segundo os valores plasmados nas leis. No caso, porém, da sua aplicação em contexto político democrático, o apego às normas legais e a sobredeterminação jurídica dos fenómenos organizacionais e das ações de gestão escolar passam a ser especialmente compatíveis com concepções procedimentalistas de democracia, isto é, limitando-a a uma democracia das formas e dos processos em prejuízo da substantividade dos objetivos, das decisões e dos conteúdos democráticos, das práticas de diálogo, de argumentação e de participação na tomada das decisões educativas. Nesse sentido, a democratização política dos regimes, outrora autoritários, e a consagração jurídica de importantes princípios de gestão democrática das escolas inscritos na legislação fundamental seriam condição suficiente para a democratização da gestão das escolas públicas. Num contexto de análise que poderia, pejorativamente, ser chamado de democratista, a gestão democrática de cada escola seria uma aquisição natural, decorrente de um regime político formalmente democrático que tivesse estabelecido legislação sobre essa matéria; mesmo nos casos em que aquela pudesse ter sido limitada a mínimos democráticos, a concepções elitistas de democracia, a práticas tecnocráticas de gestão ou a projetos educativos meritocráticos e socialmente seletivos. Ou seja, já estando subordinada a um processo de profunda erosão das políticas e das práticas de gestão democrática, mais compatível com dinâmicas características de uma “democracia governada" (BURDEAU, 1975) ou de uma "pós-democracia" (CROUCH, 2004), do que com uma interpretação expressiva dos textos jurídicos democratizantes.

Pelo contrário, a pouca exigência em termos democráticos substantivos que é marca da perspectiva anterior tenderia a ser considerada, no quadro da segunda perspectiva, como democracia a mais para gestão a menos. Isso ocorre, realmente, e com manifesto protagonismo, num vasto e diverso conjunto de teorias normativas, doutrinas de gestão e programas reformistas do Estado e da gestão pública inspirados por princípios gerencialistas. Ainda que seja difícil 
fixar com precisão as dimensões do chamado novo gerencialismo, até por referência a um gerencialismo velho, ou clássico, que compreenderia as principais ideologias de gestão, desde a "administração científica" do início do século $\mathrm{XX}$, sobressai a reforma do Estado keynesiano de bem-estar social através de processos de modernização, de supervisão, de avaliação e de prestação de contas, de contratualização e de parcerias público-privadas que, genericamente, foi associada ao "Estado gestionário" (CLARKE; NEWMAN, 1997). Uma filosofia política e económica neoliberal, baseada na liberdade dos mercados e na teoria da escolha pública, substituiu a centralidade da arena política pela centralidade do mercado, transformou eleitores em consumidores, associou partidos políticos a uma espécie de empresas em competição por votos (O'BRIEN; PENNA, 1998, p. 96), conotou todo o setor público com uma concepção pejorativa de burocracia que, de resto, seria imanente às organizações estatais e só passível de superação através da adoção da empresa privada como arquétipo institucional e de organização racional, de gestão inovadora e eficiente. De tal forma que a Nova Gestão Pública, como ideologia e corpo teórico reformista, poderá ser emblematicamente reconhecida pelas suas prescrições em direção à introdução dos princípios da gestão privada, tomados como homogéneos, no âmbito de organizações públicas representadas de forma indiferenciada, todas carecendo de um governo reinventado. A privatização, em diversos sentidos, incluindo a criação de mercados internos e a celebração de contratos de curto prazo para a prestação de serviços, passou a ser associada ao aumento da eficiência da gestão pública (LANE, 2000, p. 95). Na interpretação de Pollitt e Bouckaert (2011, p. 118-122), o que terá acontecido em grande parte das reformas realizadas na Europa continental, terá sido uma combinação de medidas só parcialmente compatíveis com a Nova Gestão Pública e a orientação para a modernização e a obtenção de resultados, com elementos considerados weberianos, incluindo a reafirmação do papel do Estado, a lei administrativa e a ideia de serviço público, de que teria resultado uma situação híbrida, mas diferenciada, que os autores designaram por "Estado Neo-Weberiano". Em qualquer caso, a Nova Gestão Pública revelou-se, em graus de intensidade muito variados consoante os países, um novo referencial reformista e, sobretudo, uma nova formação cultural e uma nova linguagem com repercussões inegáveis nas reformas do Estado e das suas organizações, desde logo através da adesão à tríade composta por desregulação, privatização e comercialização (LANE, 1997). Na educação, por exemplo, diversas práticas de gestão democrática tornaram-se ideologicamente incompatíveis e foram afastadas em vários países por força da adoção do princípio da empresarialização e privatização - como observou Stephen Ball (2007, p. 113), um "instrumento de política", um meio de reforma e de modernização do setor público. 
A pergunta que encima o presente texto, ao insistir nas dificuldades de democratização da gestão das escolas, nem subscreve a resposta formalista e tranquilizante da perspectiva jurídico-formal da qual resulta, amiúde, uma concepção democrática procedimentalista e de baixa intensidade, nem subscreve a tese de inspiração gerencialista a partir da qual se poderia afirmar que a gestão democrática representaria a adoção de um referencial irracional de gestão, exatamente numa área em que seria mais urgente substituir o poder da "burocracia profissional" (MINTZBERG, 1995) e do "corporativismo" dos professores por uma nova gestão profissional, eficiente e competitiva, com os olhos postos no exemplo da gestão das empresas privadas.

Pelo contrário, ao admitir quão difícil tem sido concretizar a democracia na gestão das escolas, mesmo em contextos políticos, constitucionais e sociais que, ao menos formalmente, aderiram a tal objetivo e o consagraram ao mais alto nível legislativo, este texto destaca várias dificuldades genéricas importantes. A primeira é a que releva da dificuldade de democratizar a gestão de uma organização tradicionalmente resistente à democracia, especialmente no contexto de regimes ditatoriais que a marcaram profundamente e por longos períodos, como aconteceu em Portugal e no Brasil. A segunda é a que destaca a relevância da democratização dos regimes políticos e da aprovação de importante legislação baseada no princípio da gestão democrática e da participação dos cidadãos enquanto condição necessária, no entanto, não suficiente para garantir uma efetiva gestão democrática das escolas. A terceira, já antes criticada, é a que acriticamente não aceita, por conveniência político-ideológica ou de outro tipo, que tendo resultado de uma conquista democrática realizada por via revolucionária ou na sequência de um processo de transição política para a democracia, a gestão democrática das escolas, entre a letra da lei, o slogan, ou o lugar-comum repetido, possa realmente encontrar-se substantivamente por cumprir e em processo de erosão do ponto de vista das políticas e das práticas. Finalmente, a dificuldade que advém da circunstância histórica e política de a gestão democrática das escolas exigir tempo suficiente para a sua consolidação, também em termos de uma ruptura cultural e educativa com práticas autoritárias e heterónomas, requerendo políticas públicas avançadas, coerentes e com continuidade, exatamente num momento que é marcado por políticas educacionais de inspiração neoliberal em várias áreas e por práticas de gestão de teor gerencialista e tecnocrático que lhe são claramente adversas. Estas e outras dificuldades de democratização da gestão escolar dão lugar a múltiplos obstáculos, alguns dos quais serão apontados seguidamente. 


\section{Dos obstáculos à democratização da gestão escolar}

Com frequência, durante a vigência de regimes políticos autoritários, os setores oposicionistas submetem a duras críticas a apresentação de propósitos governamentais de democratização da educação escolar, chamando a atenção para o fato de esta só ser possível uma vez concretizada a democratização política. Denunciando a incongruência de uma democratização da educação e da construção de uma escola democrática num contexto político não democrático, antes descortinam intenções modernizadoras, desenvolvimentistas e de formação de elites, ou de quadros técnicos, de acordo com as necessidades da economia, bem como objetivos de legitimação política dos regimes e de eventual pacificação social e gestão das crises.

Mesmo admitindo que a questão é mais complexa em termos de processo de democratização política e social, no limite aquela posição faz sentido não apenas como estratégia política de oposição, mas também em termos de política educacional, conforme foi possível concluir nos casos da democratização política de Portugal e do Brasil e dos respectivos impactos na educação, entre tantas outras áreas sociais. Contudo, é necessário reconhecer duas outras conclusões a que, em ambos os países, foi possível chegar.

A primeira relacionada com a já antes mencionada necessidade de distinguir entre a democratização política expressa, designadamente através de legislação democrática, e a sua concretização efetiva e substantiva no plano das práticas sociais e educativas, não necessariamente coincidentes, nem em termos temporais nem em termos de conteúdo. Tem-se observado como a democratização económica, social, cultural, educativa e de todo o tipo de relações de poder na sociedade é mais exigente e mais difícil de atingir do que a democratização formal das instituições políticas e das regras necessárias ao jogo interpartidário da representação eleitoral, do funcionamento dos parlamentos e dos partidos políticos, embora também aqui as crises sejam relativamente frequentes e profundas. Em ambos os casos, todavia, uma cultura democrática não se obtém rapidamente e nunca através de práticas oligárquicas, patrimonialistas ou tecnocráticas.

A segunda conclusão encontra-se associada à dimensão de processo de democratização, não apenas remetendo para dinâmicas políticas e sociais frequentemente em tensão, dando origem a contradições e a medidas descontínuas, com recepções variadas e modos de tradução diversos por parte de diferentes autoridades políticas e de diferentes contextos organizacionais, mas, sobretudo, chegando a evidenciar retrocessos vários em termos de agenda democratizadora 
e de concretização de direitos, também educacionais, que pareciam juridicamente assegurados e socialmente adquiridos, concluindo-se que não se encontram, afinal, consolidados. Em tais circunstâncias, mesmo que a legislação sobre gestão democrática das escolas seja formalmente mantida no plano das orientações para a ação, a política educacional e os atos de gestão dificilmente deixarão de fazer sentir as suas limitações no plano da ação organizacional, acabando, mais cedo ou mais tarde, por resultar em mudanças estruturais, de refluxo, consagradas em nível legislativo.

Acresce a tudo o que foi já apontado o fato de nem a atividade de gestão nem a instituição escolar terem sido historicamente construídas a partir de objetivos democráticos. Pelo contrário, tal ideal é bastante recente, tendo sido reforçado a partir do momento em que a educação foi considerada um direito humano fundamental e que à escola foram atribuídas responsabilidades de educação para todos e de formação de cidadãos democráticos, esclarecidos, com sentido crítico, preparados para o exercício de práticas democráticas e de participação ativa. Mas o modelo organizacional adotado na escola moderna, as suas estruturas e regras mais características, os seus processos de gestão, revelaram-se muito influenciados pelas organizações militares, religiosas e industriais, seja em termos de racionalização, formalização e hierarquização, seja também em termos de processos de produção em grande escala. O currículo foi socialmente hierarquizado e fragmentado, os tempos e espaços foram racionalizados e controlados, os corpos e as mentes de discentes e docentes foram disciplinados. A organização das escolas modernas e a sua gestão foram objeto de um processo de institucionalização, na longa duração, que se revelou bastante próximo das organizações produtivas do capitalismo e das teorias da gestão empresarial, sendo visíveis as influências historicamente exercidas pelo taylorismo e pelo fayolismo, por exemplo, nas teorias e nas práticas da gestão escolar, tal como continua a suceder com as mais recentes teorias da gestão da qualidade total, do "just in time", da direção por incentivos e das lideranças empreendedoras, a título de exemplo.

Não sendo inédita, esta impregnação empresarial da educação e da gestão escolar, fortemente associada à introdução de modos privados de gestão nas escolas públicas como forma de as reformar, de modernizar a sua gestão e de as tornar competitivas e performativas nunca ocorreu no passado com semelhante intensidade. Com efeito, sem recuar demasiado no tempo, a concepções fayolianas, higienistas e, até, eugenistas, nem, posteriormente, a influências exercidas pelo desenvolvimento organizacional e pela gestão por objetivos, designadamente no que se refere às pedagogias científicas e racionalizadoras, com suas propostas taxonómicas, é contudo possível concluir que é nova a intensidade, sem paralelo a difusão, quase imediata a transposição para a gestão escolar das 
teorias que, por um lado, pela facilidade e, por outro lado, pela sua diversidade interna, têm sido criticamente reunidas sob a designação genérica de gerencialismo (orientação para a gestão, excesso ou abuso no recurso a teorias da gestão de extração empresarial), ou de novo gerencialismo. Mas a sua compreensão e o seu estudo crítico mais aprofundado, de resto indispensável à própria análise e interpretação das políticas educacionais do presente e do passado recente, evitando incorrer na defesa de excepcionalismos regionais, nacionais ou locais, mas também em generalizações simplificadoras e descontextualizadas no quadro das quais tudo é considerado gerencialismo ou gerencialista, pouco ou nada se avançando nas análises, exigem o recurso a fontes primárias de ampla circulação internacional que estão longe de ter sido já suficientemente exploradas na pesquisa em educação, seja em Portugal seja no Brasil.

Tais fontes permitem localizar ideias e princípios adotados por grandes organizações internacionais, compreender melhor a origem de certas agendas e de certos discursos políticos, medidas governamentais, legislação escolar, programas de formação, conceitos entretanto naturalizados e, em particular no que se refere à temática deste texto, um importante conjunto de obstáculos, alguns dos quais novos ou renovados, à democratização da gestão da escola pública. A título de exemplo, bastará referir os impactos do movimento teórico e ideológico designado por "reinvenção do governo", seja através da obra de Osborne e Gaebler (1993) e das suas propostas de introdução do "espírito empreendedor", do "governo indireto" ou "governo empreendedor", seja através do relatório dirigido por Al Gore (1996), com as suas propostas de introdução de uma gestão de tipo empresarial na gestão pública, assim afastando a burocracia que seria típica do "Estado administrador" e adotando dinâmicas de mercado e de escolha em ambiente de concorrência entre serviços. Ou ainda considerar como Lester Salamon $(2000,2002)$ assegura que a "reinvenção do governo" e a Nova Gestão Pública já estariam em via de superação através da adopção dos princípios da "nova governança" e de seus instrumentos de ação pública de natureza colaborativa. Essas e outras propostas, não obstante as suas diferenças, partilham as mesmas lógicas de introdução da competitividade e dos contratos, de substituição de regras por padrões passíveis de medição, de substituição ou diminuição do papel de provisão direta pelo Estado através da direção, supervisão e eventual financiamento sob lógicas competitivas e de contratualização entre os setores públicos e privados, no interior do setor público, e, ainda, através de parcerias público-privadas. Esta "revolução empreendedora", que revaloriza o papel da liderança - "nada é mais importante do que a liderança" (OSBORNE; GAEBLER, 1993, p. 326) -, não apenas teve impactos posteriores nas escolas. Em certos casos as escolas representaram contextos privilegiados de teorização e de aplicação das teorias do novo gerencialismo, designadamente através da 
influência de obras seminais, como foi o caso do livro de Chubb e Moe (1990), em que os elementos democráticos presentes nas escolas públicas americanas foram claramente responsabilizados pela fraca qualidade das escolas e da educação que promoviam. A procura de escolas eficazes só seria possível, de acordo com aqueles autores, afastando das escolas as lógicas de gestão democrática, que associam a uma gestão burocrática, libertando-as da influência do sistema público de educação, dos seus professores e sindicatos, devolvendo-as aos progenitores dos alunos e às suas escolhas, bem como à comunidade, atribuindo-lhes verdadeira autonomia para se desligarem das lógicas tradicionais da gestão escolar. À semelhança das escolas privadas, o controlo democrático diretamente estabelecido sobre as escolas públicas deveria desaparecer, assim desburocratizando as escolas, tornando-as mais eficazes e responsáveis perante as escolhas da comunidade e das famílias. Uma visão clara, objetivos estabelecidos rigorosamente e com ambição, lideranças educacionais mais fortes, professores mais profissionais, famílias com capacidade de exercer a escolha da escola, estariam na base de escolas mais eficazes e com melhores resultados. Descentralização, competição e escolha seriam os segredos da escola eficaz, incompatíveis com lógicas de gestão e de controlo democráticos; "mercados", não "democracias", seriam os referenciais mais compatíveis com escolas em busca da excelência académica.

Para além dos impactos políticos, organizacionais e gestionários daquelas ideologias, têm ocorrido alterações significativas na cultura escolar, nos modelos pedagógicos e de avaliação, no currículo, na formação docente, nos comportamentos de professoras e educadores profissionais, em geral suscitadas pelo não reconhecimento de importantes especificidades da educação e das escolas, dessa forma procurando tornar mais fácil o processo da sua impregnação empresarial e gerencialista. Considerem-se, por exemplo, os seguintes elementos: a) a formação e a cultura profissional dos professores e dos gestores escolares são coincidentes, ao contrário do que acontece na maioria das organizações complexas; b) os alunos não são simplesmente usuários, e não são clientes da escola pública, são participantes e têm direitos enquanto tal, além de pertencerem à organização, ou seja, de serem membros da escola; c) os professores, na sua ação, dependem em grande parte dos seus alunos e só ensinam verdadeiramente se estes quiserem aprender, uma vez que não existe verdadeiro ensino sem aprendizagem; d) as doutrinas, os métodos e as técnicas de gestão empresarial não só se revelam, frequentemente, de difícil aplicação às escolas, como, em muitos casos, é mesmo impossível aplicá-los sem correr o risco de transformar a gestão escolar num ato deseducativo; e) os objetivos educativos não são apenas distintos dos da produção material e da obtenção de lucro, além disso são muito complexos, ambíguos e difíceis de definir a priori com rigor, mesmo conside- 
rando o regresso às pedagogias científicas e racionalizadoras, aos resultados de aprendizagem, às metas, aos indicadores, aos padrões e às evidências; f) as tecnologias organizacionais das escolas, isto é, os seus processos educativos e didáticos, revelam uma grande incerteza, são pouco fidedignos, não produzem sempre os mesmos resultados, não se compreendendo, por isso mesmo, o recurso às metáforas produtivistas e mecanicistas, como se cada aluno fosse uma espécie de matéria-prima moldável e imediatamente comparável.

Tudo isso, porém, tende a ser esquecido sempre que se trata de propor a empresarialização das escolas ou do seu modo de gestão, assente na hegemonia do novo capitalismo e na sua rejeição de todas as concepções de educação como realidades extraeconómicas, para além da formação de capital humano e da produção de qualificações ao serviço da competitividade económica. Contudo, a democracia e as práticas de colegialidade democrática, a autonomia como participação nas decisões e capacidade de produção de regras próprias, em direção às formas de endogoverno democrático, estão longe de constituir simples técnicas de gestão, ou mesmo somente princípios políticos constitucionalmente legitimados em certos casos. Mais do que tudo isso, são práticas educativas e de aprendizagem da democracia através do exercício da participação nos processos de tomada das decisões e um direito de professores, alunos, famílias e entorno comunitário.

\section{Concluindo: quão democrática é a gestão democrática da escola pública?}

Correndo o risco de vir a ser subordinada à razão técnica, às práticas democráticas ritualizadas e às encenações participativas mais congruentes com o governo heterónomo das escolas e a sua direção atópica, situada acima e para além de cada escola concreta e de seus atores, a gestão democrática da escola pública pode ser transformada de princípio jurídico democrático em complexo de práticas sem sentido democrático substantivo, em processo de erosão. Sabendo que quer como princípio e direito legalmente reconhecido, quer como realização efetiva no plano da ação e das práticas dos atores, a gestão democrática da escola é sobretudo um processo contínuo e nunca concluído de aprofundamento e de vivência da democracia nas escolas, a questão crucial a ser pesquisada e respondida, a cada momento e em cada contexto escolar concreto, é a de saber quão democrática é, e está sendo, a legalmente instituída e discursivamente onipresente gestão democrática da escola. A pergunta não é apenas justificada pela necessidade de estudar empiricamente, do ponto de vista político e so- 
ciológico, as práticas de gestão democrática em curso nas escolas e os seus diferentes modos de apropriação e recontextualização em contextos de ação concreta. Também do ponto de vista intrinsecamente democrático a questão é incontornável, sabendo-se que a democracia na escola é também uma questão de grau, dependente de estruturas, regras, processos e práticas efetivas de eleição, colegialidade e participação na tomada das decisões (LIMA, 2014), relações com as autoridades e outras instituições, capacidade de dialogar, argumentar, ter voz, etc. Não há, como se sabe desde Rousseau e de outros autores clássicos, outro processo de ensinar e aprender a democracia e de conseguir interessar cada um de nós pelos assuntos relativos ao governo da coisa pública que não seja através do exercício da democracia e da participação, da cidadania ativa.

Contraditoriamente, a "firma", como observou Crouch (2004), tem sido tomada como arquétipo racional e tecnicamente superior, como instituição promotora do empreendedorismo e da inovação, através de formas mínimas de participação e de concepções elitistas e formalistas de democracia. De modo semelhante, a atividade de gestão aparece genericamente associada a líderes unipessoais com poderes reforçados em termos de autonomia de gestão, de controlo e de escrutínio sobre a ação de docentes e discentes, embora frequentemente em situação de ampla subordinação perante as autoridades políticas nacionais ou locais. A colegialidade democrática surge, nesse contexto, como um valor denegado ou de importância diminuída, dado que assim se torna mais fácil atomizar cada diretora e isolar cada professor, do que resulta que o trabalho cooperativo e a solidariedade entre uns e outros é mais difícil de alcançar, antes favorecendo a hierarquização e a competição. Mas imitando as organizações empresariais, a escola pública sai democraticamente deslegitimada, prescinde das suas especificidades, aliena as suas responsabilidades éticas, políticas e morais, para além de contribuir para a alienação dos docentes, enclausurando-os em programas e metas, em injunções didatistas, num regime avaliocrático e quantofrénico, aprisionando-os em programações, plataformas informáticas, novas formas de organização do trabalho e modalidades de supervisão direta. E, no entanto, à medida que o corpo docente vai perdendo a capacidade de decidir sobre questões educativas relevantes e de implicar seus alunos e outros atores nelas, no contexto de uma democracia escolar reduzida a mínimos e de uma autonomia da escola sobretudo retórica, emerge um novo ativismo instrumental nas escolas e mesmo a ideia de um grande "envolvimento" dos profissionais, embora, paradoxalmente, estes pareçam decidir cada vez menos e com menos liberdade. O participacionismo, como lhe chamou Maurício Tragtenberg (1989), tende a ser vazio de decisões relevantes, situação em que uma gestão democrática da escola em pouco se distinguiria, do ponto de vista substantivo, de uma gestão tecnocrática ou autocrática. 
A gestão democrática da escola não é apenas, nem sobretudo, um problema organizacional e de gestão, mas antes uma questão central ao processo de democratização da educação, de expansão e realização do direito à educação, de possibilidade de educar para e pela democracia e a participação. Com efeito, a gestão democrática implica a assunção de especiais responsabilidades na organização e no governo das escolas, tendo em vista concretizar o direito à educação, não só na lógica da provisão pública mas também na lógica da promoção dos direitos humanos e da participação dos implicados na organização e gestão da educação. Ao contrário do que muitos supõem, é por esta razão que a gestão democrática é parte constituinte do próprio currículo escolar lato sensu considerado, não só um contexto ou um modelo de gestão, mas também uma das dimensões do processo educativo.

Não é possível ensinar nem aprender a democracia, a participação e a cidadania ativa em contextos escolares e através de processos de governo autocráticos, sob práticas elitistas e oligárquicas, subjugadas a líderes autoritários e a dinâmicas patrimonialistas, ou ao império da racionalidade técnico-instrumental. E especialmente nas escolas, como lembrou John Dewey no seu livro clássico Democracia e Educação, "A democracia é mais do que uma forma de governo; é, antes de mais, uma forma de vida associativa, uma experiência partilhada em conjunto" (DEWEY, 2007, p. 88). Nesse sentido, a democracia encerra uma dimensão claramente educativa e, pelo menos em sentido metafórico, também uma didática própria, baseada no exercício continuado da participação ativa, do diálogo e do debate entre posições distintas ou em conflito. E por isso se compreende quão difícil é democratizar a educação e remover das escolas os principais obstáculos políticos, organizacionais, de governo e de gestão, de relações de poder, de teorias e de objetivos educacionais que as vêm impedindo, há séculos - e mesmo em regimes políticos formalmente democráticos -, de se afirmarem como organizações educativas democráticas.

\section{REFERÊNCIAS}

BALL, S. J. Education plc. Understanding private sector participation in public sector education. Londres: Routledge, 2007.

BARROSO, J. A formação em administração educacional em Portugal. In: LUÍS, A.; BARROSO, J.; PINHAL, J. (Orgs.). A administração da educação: investigação, formação e práticas. Lisboa: Fórum Português de Administração Educacional, 1997. p. 85-104. 
BURDEAU, G. A democracia: ensaio sintético. Mem Martins: Publicações Europa-América, 1975.

CHUBB, J. E.; MOE, T. M. Politics, markets and America's schools. Washington D. C.: The Brookings Institution, 1990.

CLARKE, J.; NEWMAN, J. The managerial state: Power, politics and ideology in the remaking of social welfare. Londres: Sage, 1997.

CROUCH, C. Post-Democracy. Cambridge: Polity Press, 2004.

DEWEY, J. Democracia e educação. Lisboa: Didáctica Editora, 2007.

GORE, A. (Dir.) Da burocracia à eficácia: reinventar a administração pública. Lisboa: Quetzal, 1996.

LANE, J.-E. Incorporation as public sector reform. In: LANE, J.-E. (Org.). Public sector reform: Rationale, trends and problems. Londres: Sage, 1997. p. 283-300.

LANE, J.-E. New public management. Londres: Routledge, 2000.

LIMA, L. C. O ensino e a investigação em administração educacional em Portugal: situação e perspectivas. In: AAVV, Ciências da educação em Portugal: situação e perspectivas. Porto: Sociedade Portuguesa de Ciências da Educação, 1991. p. 91-117.

LIMA, L. C. Para o estudo da evolução do ensino e da formação em administração educacional em Portugal. Revista da Faculdade de Educação, v. 23, n. 1/2, p. 91-123, 1997.

LIMA, L. C. A escola como organização educativa. Uma abordagem sociológica. 4. ed. São Paulo: Cortez, 2011.

LIMA, L. C. A gestão democrática das escolas: do autogoverno à ascensão de uma pós-democracia gestionária? Educação e Sociedade, v. 35, n. 129, p. 1067-1083, 2014.

MINTZBERG, H. Estrutura e dinâmica das organizações. Lisboa: Publicações Dom Quixote, 1995.

O'BRIEN, M.; PENNA, S. Theorizing welfare. Enlightenment and modern society. Londres: Sage, 1998.

OSBORNE, D.; GAEBLER, T. Reinventing government: How the entrepreneurial spirit is transforming the public sector. New York: Plume, 1992.

POLLITT, Ch.; BOUCKAERT, G. Public management reform. Oxford: Oxford University Press, 2011.

SALAMON, L. M. The new governance and the tools of public action: An introduction. Fordham Urban Law Journal, v. 28, n. 5, p. 1611-1674, 2000.

SALAMON, L. M. The new governance and the tools of public action: An introduction. In: SALAMON, L. M. (Ed.). The tools of government: A guide to the new governance. Oxford: Oxford University Press, 2002. p. 1-47. 
SANDER, B. Gestão da educação na América Latina: construção e reconstrução do conhecimento. Campinas: Autores Associados, 1995.

SILVA, G. Modelos de formação em administração educacional. Braga: Universidade do Minho, 2006.

SOUZA, A. R. A produção do conhecimento e o ensino da gestão educacional no Brasil. Revista Brasileira de Política e Administração da Educação, v. 24, n. 1, p. 51-60, 2008.

TORRES, L. L.; LIMA, L. C. Formação e investigação em administração educacional em Portugal. Espaço do Currículo, v. 10, n. 1, p. 29-48, 2017.

TRAGTENBERG, M. Administração, poder e ideologia. São Paulo: Cortez Editora, 1989.

Texto recebido em 18 de janeiro de 2018. Texto aprovado em 30 de janeiro de 2018. 